Summary of results

\begin{tabular}{|c|c|c|c|}
\hline Case No & $\begin{array}{l}\text { Computed tomographic } \\
\text { measurements of } \\
\text { trabecular bone density } \\
\text { in L2-4 (\% ratio of } \\
\text { 2nd:1st measurements) }\end{array}$ & $\begin{array}{l}\text { Dual photon } \\
\text { measurements of bone } \\
\text { mineral content on right } \\
\text { mid-femur shaft } \\
(\% \text { ratio of } 2 \mathrm{nd}: 1 \mathrm{st} \\
\text { measurements) }\end{array}$ & $\begin{array}{c}\text { Serum oestradiol } \\
-17 \beta(\mathrm{pmol} / \mathrm{l}) \text { after } \\
3 \text { months' treatment }\end{array}$ \\
\hline 1 & $90 \cdot 3$ & $100 \cdot 5$ & 193 \\
\hline 2 & $95 \cdot 3$ & 100.6 & 79 \\
\hline 3 & $87 \cdot 6$ & 97.9 & 144 \\
\hline 4 & - & $100 \cdot 0$ & 205 \\
\hline 5 & $96 \cdot 8$ & 96.9 & 48 \\
\hline 6 & $86 \cdot 2$ & $96 \cdot 4$ & 77 \\
\hline 7 & $107 \cdot 3$ & $98 \cdot 8$ & 224 \\
\hline 8 & 92.5 & $98 \cdot 8$ & 145 \\
\hline 9 & 109.9 & $99 \cdot 4$ & 48 \\
\hline 10 & 101.9 & $101 \cdot 9$ & 130 \\
\hline 11 & 93.9 & $99 \cdot 4$ & 71 \\
\hline 12 & 93.5 & $99 \cdot 3$ & 279 \\
\hline 13 & 91.0 & $98 \cdot 6$ & 196 \\
\hline $\begin{array}{l}\text { Mean (SEM) } \\
\star \text { Significance }\end{array}$ & $\begin{array}{c}95 \cdot 4(2 \cdot 1) \\
p=0.06\end{array}$ & $\begin{array}{c}99 \cdot 1(0.4) \\
p=0.06\end{array}$ & $141(21)$ \\
\hline
\end{tabular}

^Paired Student's $t$ test.

The data presented suggest that any increased trabecular bone loss seen in patients receiving luteinising hormone releasing hormone agonist treatment might be a factor in determining both the duration of treatment and the timing of possible repeated courses in premenopausal women receiving such agonists for the treatment of benign gynaecological conditions.

We thank Hoechst-Roussel (United States) for supporting WHM and funding bone density studies and Dr P Magill (Hoechst-UK) for supplying Buserelin. We also thank Dr J Reeve (Clinical Research Centre, Northwick Park Hospital) and Dr R Evans (radiology department, Northwick Park Hospital) for their continued support and advice.

1 Healy DL, Fraser HM, Lawson SL. Shrinkage of a uterine fibroid after subcutaneous infusion of LHRH agonist. BrMed I 1984;289:1267-8.

2 Shaw RW, Fraser HM, Boyle H. Intranasal treatment with luteinsing hormone releasing hormon agonist in women with endometriosis. Br Med $\mathcal{J}$ 1983;287:1667-9.

3 Cann CE, Genant HK. Precise measurement of vertebral mineral content using computed tomography. $f$ Comput Assist Tomogr 1980;4:493-500

4 Krølner B, Nielsen SP. Measurement of bone mineral content (BMC) of the lumbar spine. I. Theory and application of a new two-dimensional dual-photon attenuation method. Scand $\mathcal{F}$ Clin Lab Invest 1980;40:653-63.

5 Genant HK, Cann CE, Ettinger B, Gordan GS. Quantitative computed tomography of vertebral spongiosa: a sensitive method for detecting early bone loss after oophorectomy. Ann Intern Med 1982;97:699.

(Accepted 13 February 1987)

Academic Department of Obstetrics and Gynaecology, Royal Free Hospital, London NW3 2QG

W H MATTA, MRCOG, clinical research fellow

R W SHAW, MRCOG, FRCS, professor

Radio-isotopes Division, Clinical Research Centre and Radiology Department, Northwick Park Hospital, Harrow, Middlesex HA1 3UJ

R HESP, BSC, MINSTP, Medical Research Council scientific staff

D KATZ, FRCR,consultant radiologist

Correspondence to: Mr Matta.

\section{Pyomyositis associated with human immunodeficiency virus infection}

Pyogenic intramuscular abscesses (pyomyositis) are rare in temperate climates. Their cause is unknown, but trauma, travel to the tropics, diabetes, drug abuse, and neutropenia have been associated. ${ }^{1}$ We report a case occurring in a homosexual man with antibodies to the human immunodeficiency virus (HIV) and none of the recognised risk factors.

\section{Case report}

A 52 year old white homosexual man presented with a two month history of malaise and a painful lump in the right thigh. There was a history of syphilis and of acute allergic vasculitis, which had settled spontaneously. He denied any sexual contact for seven years. There was no history of drug abuse, trauma, or recent travel abroad.
On examination he was feverish $\left(38^{\circ} \mathrm{C}\right)$. There was erythema overlying a mass in the right thigh measuring $6 \times 4 \mathrm{~cm}$. Physical examination showed nothing remarkable except an anal ulcer. Further investigation showed: haemoglobin 122 $\mathrm{g} / \mathrm{l}$, white cell count $5 \cdot 2 \times 10^{9} / 1$, Westergren erythrocyte sedimentation rate (ESR $56 \mathrm{~mm}$ in first hour, and albumin $32 \mathrm{~g} / \mathrm{l}$. There was serological evidence of previous syphilitic infection. Enzyme linked immunosorbent assay (ELISA) for HIV antibodies was positive. Blood cultures on three occasions were sterile. Ultrasound scanning showed an intramuscular necrotic mass (figure), and an abscess was found at open biopsy. The pus was sterile, and histological examination of the abscess wall showed non-specific inflammation without evidence of malignancy. Fever persisted after the operation, intravenous gentamicin and flucloxacillin were given for 48 hours, and the abscess healed. Intercurrent oropharyngeal candidiasis responded to amphotericin. The patient has subsequently developed a progressive encephalopathy.

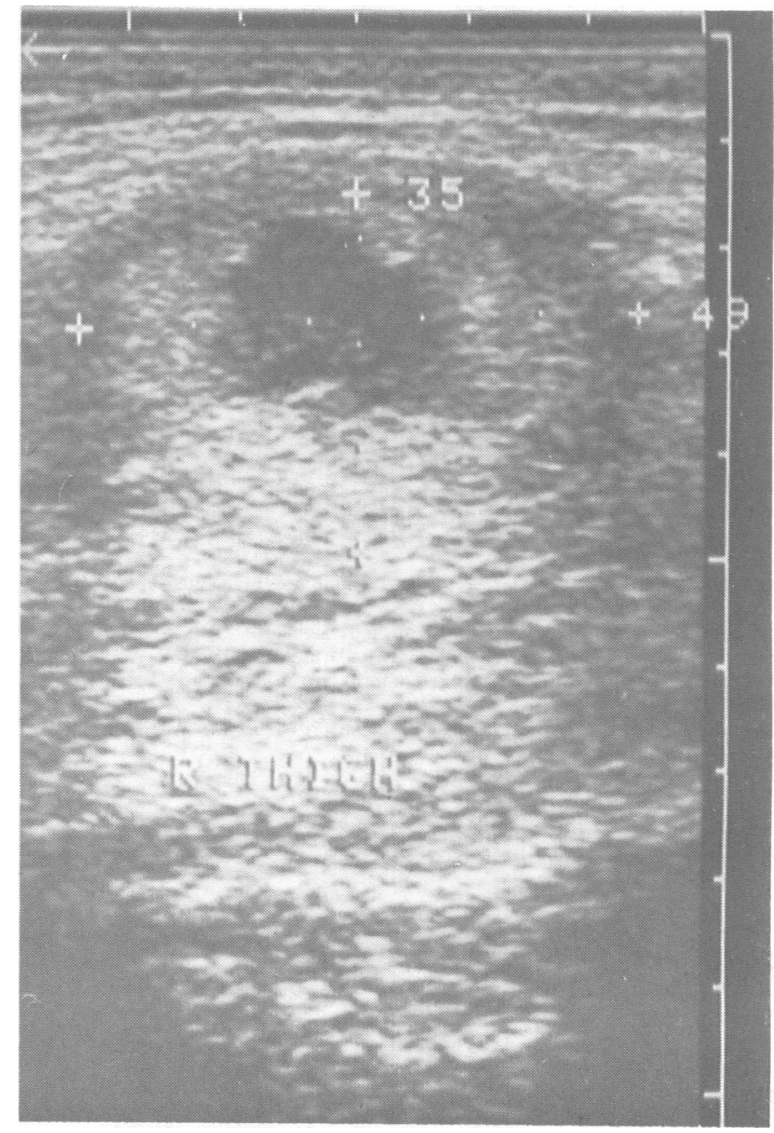

Ultrasound scan of right thigh showing an intramuscular necrotic mass.

\section{Comment}

Pyomyositis is common in the tropics, where it accounts for $4 \%$ of surgical admissions and is associated with trauma, poor nutrition, and acute viral infections. ${ }^{2} 3$ The incidence in temperate climates is unknown, and reports of pyomyositis in the indigenous populations are rare $^{14}$; when it does occur it is associated with recent travel to the tropics, trauma, diabetes, and drug abuse. ${ }^{1}$

Presentation is with painful swelling of a large muscle, which becomes increasingly hard and indurated, described typically as "woody hard," before eventually becoming fluctuant. There may be accompanying fever, malaise, anaemia, leucocytosis, and raised erythrocyte sedimentation rate. Sites commonly affected are the quadriceps and gluteal muscles, and multiple abscesses occur in $60 \%$ of cases. ${ }^{1}$ Most cases occur in children and men aged $20-45$ years. ${ }^{1 \cdot 3}$

The differential diagnosis of pyomyositis includes sarcoma, haematoma, and cellulitis. Methods of diagnosis include needle aspiration, ultrasonography, and computed tomography. Diagnosis is hard in the early stages because the classical signs of inflammation are not present; differentiation from sarcoma may be difficult. ${ }^{15}$ Needle aspiration yields pus from which an organism may be identified. Ultrasonography will show an abscess cavity and assists aspiration. Staphylococcus aureus can be cultured in about $85 \%$ of cases but is cultured from blood in fewer than $5 \%$ of cases. ${ }^{13}$ The remainder are associated with a range of infections, and no organisms are isolated in $4.5 \%$ of cases. ${ }^{13}$ 
Our patient presented with typical features of pyomyositis: fever, malaise, and a tender hard mass. Ultrasonography suggested either an abscess or a necrotic tumour, and the diagnosis was made by open biopsy. No causative organism was identified. He had none of the known risk factors. He was, however, positive for HIV antibodies, and associated immunosuppression was possibly a factor in the development of the muscle abscess, although at the time of writing he had not developed any further infections apart from oropharyngeal candidiasis. Pyomyositis has not been reported in association with HIV.

Pyomyositis is uncommon in Britain and is not usually recognised. Familiarity with its features should result in the diagnosis being made more readily. It may prove to be a well recognised feature of infection with HIV and require differentiation from sarcoma.

1 Gibson RK, Rosenthal SJ, Lukert BP. Pyomyositis: increasing recognition in temperate climates. Am J Med 1984;77:768-72.

2 Horn CV, Master S. Pyomyositis tropicans in Uganda. East Afr Med f 1968;45:463-71.

3 Chiedozi LC. Pyomyositis. A review of 205 cases in 112 patients. Am I Surg 1979;137:255-9.

4 Rogers DW. Case of pyomyositis occurring in London. Br Med 7 1973;iii:679.

5 Reid SE, Nambisan R, Karakousis CP. Pyomyositis: a differential diagnosis from sarcoma. $f$ Surg Oncol 1985;29:143-6.

(Accepted 5 March 1987)

Departments of Medicine, Orthopaedic Surgery, and Radiology, Whittington Hospital, London N19 5NF

R A WATTS, MA, MRCP, medical registrar

B I HOFFBRAND, DM, FRCP, consultant physician

D F PATON, FRCS, consultant orthopaedic surgeon

J C DAVIS, FRCR, consultant radiologist

Correspondence to: Dr Watts.

\section{Myocardial infarction due to amphetamine}

We report on a patient with myocardial infarction probably resulting from self administration of intravenous amphetamine.

\section{Case report}

A 33 year old white building labourer was admitted with chest pain. He was a known drug addict, taking 500-750 mg of heroin intravenously each week and occasionally taking other substances. One hour before the onset of his pain he had injected himself with about $60 \mathrm{mg}$ of amphetamine, having injected $40 \mathrm{mg}$ of heroin several hours earlier. Two years previously he had been admitted with similar chest pain; at the time no history of drug abuse was elicited, but later he had admitted to taking amphetamine intravenously one hour before. He cleaned his needles in hot water and occasionally shared needles. He smoked about 20 cigarettes a day and drank alcohol occasionally. His mother had died of myocardial infarction at the age of 41 .

On admission he was drowsy and in pain. There were no abnormal signs apart from venepuncture scars on his arms. Serial electrocardiograms showed the development of abnormal $Q$ waves and typical ST-T segment changes due to an inferolateral myocardial infarct (figure). Peak serum enzyme concentrations were raised: aspartate aminotransferase $235 \mathrm{IU}$ (normal 15-40 IU/1) and lactate dehydrogenase $708 \mathrm{IU} / 1$ (normal 115-235 IU/1). Blood glucose concentration measured at random was normal at $5.6 \mathrm{mmol} / \mathrm{l}$. Results of serological tests for human immunodeficiency virus were negative. Hepatitis $B$ surface antibody was present in low titre, but hepatitis B surface antigen and e antigens were absent. On his previous admission pericarditis had been diagnosed, but enzyme concentrations were not measured. Electrocardiograms at that time showed changes compatible with a non- $Q$ wave anterolateral infarct.

He made an uneventful recovery from his presumed second infarct and had no withdrawal symptoms. On discharge from hospital seven days later he was not receiving any drugs. At follow up he denied smoking or taking drugs. Coronary arteriograms performed three months after the infarction were normal. A left ventricular angiogram was also normal apart from slightly diminished apical contraction. Blood lipid concentrations were normal, with a cholesterol concentration of $5.2 \mathrm{mmol} / \mathrm{l}$.

\section{Comment}

Amphetamine is a sympathomimetic drug which acts by releasing noradrenaline from sympathetic nerve endings. Catecholamines can cause myocardial damage by increasing myocardial oxygen demand or by causing platelet aggregation. In animals pretreatment with antiplatelet drugs may prevent catecholamine induced myocardial necrosis. ${ }^{1}$ Noradrenaline usually causes dilatation, but in some people it may cause coronary artery spasm. ${ }^{2}$ As far as we are aware acute myocardial ischaemia due to heroin has not been reported, although this drug is known to cause pulmonary oedema, arrhythmias, and hypoxia.

Congestive cardiomyopathy has been reported in a woman who used oral dextroamphetamine almost continuously for 12 years $^{3}$ and in four men who regularly used intravenous propylhexedrine, an amphetamine analogue. ${ }^{4}$ In three of these cases coronary arteriograms were normal. There have been two reports of acute cardiomyopathy related to intravenous amphetamine abuse, and in both cases coronary arteriograms were normal. ${ }^{15}$

It is increasingly recognised that myocardial infarction may occur in patients with subsequently normal coronary arteriograms. The mechanism is uncertain, but lysis of thrombus and coronary artery spasm are common explanations.

Our patient had known risk factors for coronary artery disease: he smoked cigarettes and his mother had died of myocardial infarction at the age of 41 . His coronary arteries appeared normal, however, and his two episodes of

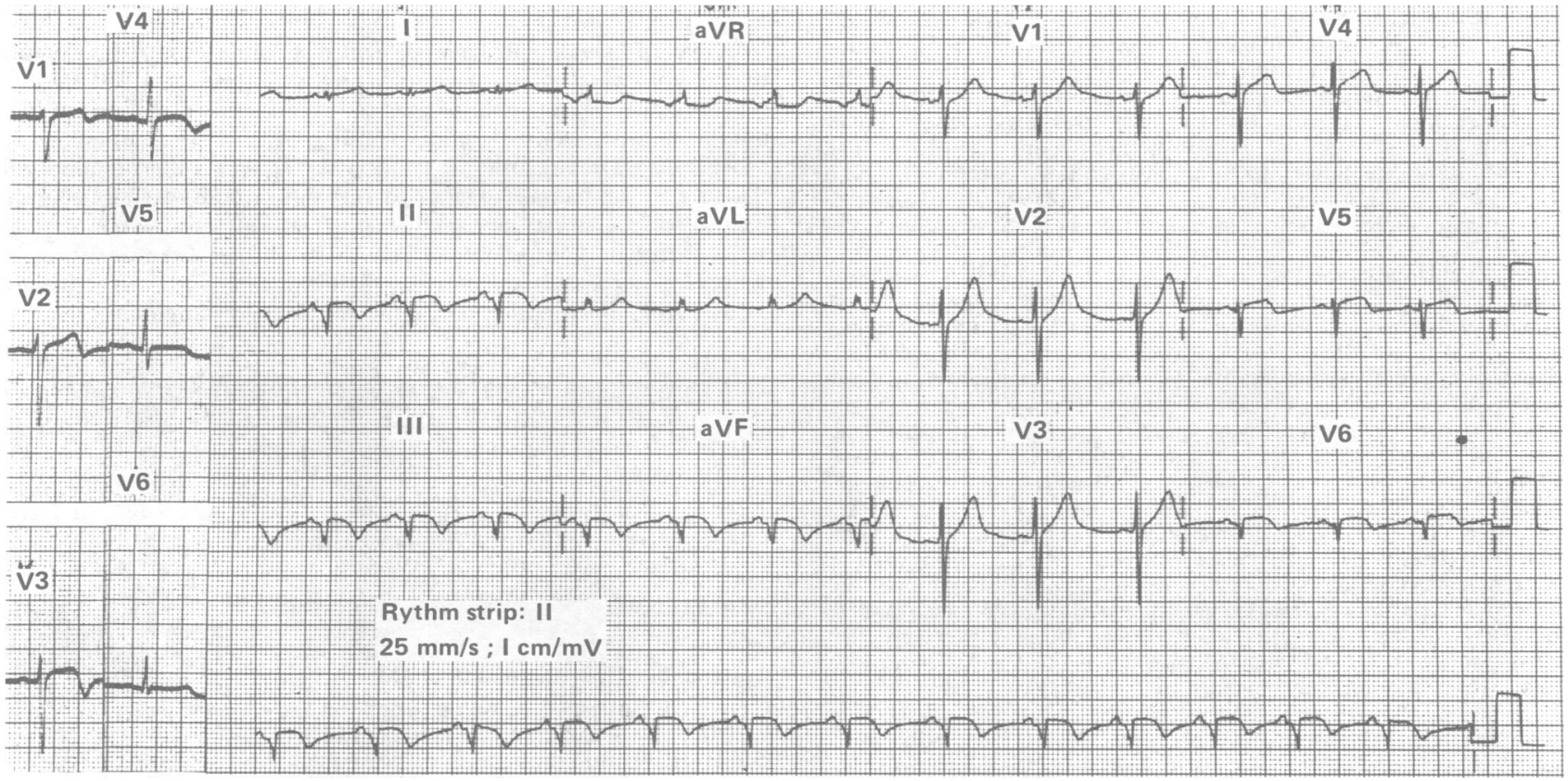

Left. Chest leads of the electrocardiogram taken on admission two years previously. They show slight ST segment elevation in V2-3, with terminal T wave inversion in V1-3, T wave inversion in V4, and $\mathrm{T}$ wave flattened in V5. Right. Twelve lead electrocardiogram taken on recent admission showing abnormal $Q$ waves in II, III, AVF, and V6, and ST segment elevation with T wave inversion in these leads. 